\title{
NULIDAD E INEXISTENCIA DE LOS ACTOS JURÍDICOS EN EL DERECHO ECUATORIANO (I)
}

NULLITY AND INEXISTENCE OF LEGAL ACTS IN ECUADORIAN LAW

\author{
César Coronel Jones ${ }^{*}$ \\ Óscar Del Bruto Andrade
}

Resumen: La inexistencia y la nulidad son instituciones fundamentales para el derecho privado ecuatoriano. Se trata de dos categorías distintas que tienen en común perseguir la ineficacia de los actos que no se formaron de acuerdo a los parámetros jurídicos. Tratándose de actos inexistentes, la ley los priva de toda consecuencia jurídica. Tratándose de actos nulos, la ley permite que un juez declare su invalidez y desconozca sus efectos. Este artículo revisa la regulación legal de la inexistencia y la nulidad en el derecho ecuatoriano, así como los pronunciamientos al respecto de la Corte Nacional de Justicia.

Palabras clave: Actos jurídicos, ineficacia, inexistencia, nulidad absoluta, nulidad relativa

Abstract: Inexistence and nullity of juridical acts are basic institutions in Ecuadorian Law. These are two different categories that have in common the chasing of the invalidity of the juridical acts that didn't form according to Law. Inexistent acts are deprived by the law of any legal effect, while null acts have legal effects but a judge can declare them null and erase their legal effects that have already taken place. This paper reviews the legal regulation of inexistent and nullity under

* Profesor de Derecho Civil en la Universidad Católica Santiago de Guayaquil (Ecuador).ccoronel@coronelyperez.com

** Ayudante de la cátedra de Responsabilidad Civil en la Universidad Católica Santiago de Guayaquil (Ecuador). oscar_delbrutto@hotmail.com 
Ecuadorian Law, as well as the rulings of the National Court of Justice regarding the issue.

Key words: Juridical acts, inefficiency, inexistence, nullity, absolute nullity, relative nullity

Fecha de recepción: 28-11-2011

Fecha de aceptación: 15-12-2011

\section{INTRODUCCIÓN}

La ley establece algunos presupuestos para que un acto jurídico $^{1}$ se tenga por existente y por válido. Cuando aquellos presupuestos no se cumplen, la ley manda que se desconozca totalmente el acto o que se lo prive de eficacia. La inexistencia y la nulidad son las instituciones jurídicas que sirven para esos propósitos en el derecho privado. En realidad, se trata de instituciones fundamentales para la teoría general del derecho, porque persiguen mantener el imperio de la ley y nos permiten diferenciar los supuestos en los que un acto debe ser protegido por el derecho y los supuestos en los que un acto no debe tener tal protección.

Al igual que ocurre con todas las instituciones fundamentales de derecho privado en la legislación de nuestro país, la inexistencia y la nulidad están tratadas en el Código Civil. La inexistencia no está especialmente regulada, pero su régimen resulta de sistematizar algunas disposiciones dispersas a lo largo

${ }^{1}$ La expresión "acto jurídico" está tomada aquí en su acepción amplia de "toda declaración de voluntad encaminada a producir efectos jurídicos". El contrato es el principal acto jurídico para el derecho privado, pero lo que será dicho en este trabajo no es aplicable sólo a los contratos, sino que aplica para todo tipo de acto jurídico de derecho privado.

Ius Humani, v. 2 (2010/11), p. 178 
del Código. La nulidad, en cambio, sí está especialmente regulada en el Código Civil, que le dedica el Título XX del Libro Cuarto, además de algunas disposiciones ubicadas en otros títulos. Estas normas fueron diseñadas teniendo en cuenta principalmente la nulidad de los contratos de derecho privado, pero constituyen derecho común, por lo que son aplicables a todos los actos que no tienen una regulación especial y, también, a los actos que tienen una regulación especial, en cuanto a los vacíos de esa regulación ${ }^{2}$. En concordancia con este último punto, la Corte Nacional de Justicia $^{3}$ ha fallado que lo previsto sobre nulidad en el Libro IV del Código Civil aplica para la nulidad de los testamentos ${ }^{4}$, y que los contratos de derecho público pueden ser invalidados aplicando las causales de nulidad previstas en el Código Civil ${ }^{5}$.

Las sentencias de la Corte Nacional de Justicia en las que se resuelve sobre la existencia y validez de un acto jurídico son muy frecuentes $^{6}$, y la mayoría de los autores han desarrollado

2 Esto es una consecuencia de que el derecho civil tenga el carácter de supletorio y de derecho común. En este sentido el artículo 4 del Código Civil ecuatoriano. (Vodanovic, Curso de Derecho Civil Parte General, 1961, pág. 6).

${ }^{3}$ Muchos de los fallos que serán citados aquí fueron expedidos por la "Corte Suprema de Justicia”, que era la denominación que tenía el Tribunal de casación en el Ecuador hasta el año 2008, en que, en virtud de la nueva Constitución, pasó a denominarse "Corte Nacional de Justicia". Para simplificar la lectura, nos vamos a referir simplemente a la "Corte Nacional de Justicia" en todos los casos.

${ }^{4}$ Cfr. Parra vs. Samaniego, 14 de febrero de 2006, Gaceta Judicial Serie XVIII No. 2.

${ }^{5}$ Cfr. Municipio de Quito vs. Desaci, 28 de octubre de 1999, Gaceta Judicial Serie XVII No. 2; Contraloría General del Estado vs. Municipalidad de Cuenca et al., 18 de marzo de 2003, Gaceta Judicial Serie XVII No. 12.

${ }^{6}$ Este trabajo considera todos los fallos de casación sobre inexistencia y nulidad de actos jurídicos que han sido publicados en las Gacetas Judiciales. Dichos fallos llegan a ser más de noventa, lo que da una clara idea de lo común que son los juicios que versan sobre la inexistencia y la nulidad en la práctica del Derecho en nuestro país. 
explicaciones doctrinarias sobre los actos inexistentes y nulos ${ }^{7}$. Tanto en la jurisprudencia como en la doctrina, el tema es abordado ubicando en un extremo a los actos perfectos y, junto a ellos, a los actos imperfectos, de acuerdo al grado de su imperfección: actos inexistentes, actos nulos absolutamente y actos nulos relativamente.

\section{INEXISTENCIA}

\subsection{Régimen del acto inexistente}

La inexistencia constituye la categoría más radical de imperfección en la que se puede ubicar a un acto en el derecho privado (Vélez, 1924, pág. 374; Valencia \& Ortíz, 2000, pág. 519; Claro, 1979, pág. 582; Vodanovic, 1942, pág. 311; Ospina \& Ospina, 2000) ${ }^{8}$. Un acto jurídico es inexistente cuando carece de los requisitos que la ley considera esenciales para su perfeccionamiento (Vélez, 1924, pág. 374; Claro, 1979, pág. 581; Valencia, 1979, pág. 519; Vodanovic, 2004, pág. 312; Ospina \& Ospina, 2000). Son requisitos esenciales de un acto los que según la ley constituyen su núcleo o sustancia, es decir, aquellos sin los cuales ese acto pierde su identidad propia. Según un ejemplo clásico, son elementos esenciales de la compraventa la cosa vendida y el precio; si falta cualquiera de los dos se entiende que la compraventa no existe jurídicamente.

Los requisitos esenciales de cualquier acto jurídico en el derecho privado son la voluntad, la causa, el objeto y las

\footnotetext{
${ }^{7}$ Este trabajo considera especialmente la doctrina de los colombianos Fernando Vélez, Arturo Valencia, Álvaro Ortiz, Guillermo Ospina y Eduardo Ospina; y de los chilenos Luis Claro, Arturo Alessandri Rodríguez, Manuel Somarriva, Antonio Vodanovic, René Abeliuk y Arturo Alessandri Besa. Se ha considerado especialmente a estos autores por ser los más citados en los fallos de casación que se refieren a materias civiles en el Ecuador.

${ }^{8}$ En la jurisprudencia, cfr. Altabar vs. Salgado, 16 de mayo de 2001, Gaceta Judicial Serie XVII No. 6.
}

Ius Humani, v. 2 (2010/11), p. 180 
formalidades cuando son establecidas como solemnidad (Claro, 1979, págs. 582-590; Alessandri Besa, 2011, pág. 22; Vodanovic, 2004, pág. 312) ${ }^{9}$. Si cualquiera de esos requisitos falta, el acto jurídico se tiene por inexistente. Así, por ejemplo, es inexistente el contrato de compraventa en el que sólo comparece una de las partes, porque falta la voluntad de la otra; es inexistente el arrendamiento en que no se establece la obligación del arrendador de entregar la cosa para el uso del arrendatario, porque falta la causa; es inexistente la donación en la que no hay un bien donado, porque falta el objeto; $y$, es inexistente la permuta de un inmueble que no se hace por escritura pública, porque falta la solemnidad.

La consecuencia de que no se cumplan los requisitos esenciales, es que el acto no alcance a perfeccionarse y que no produzca ni obligaciones civiles ni obligaciones naturales ${ }^{10}$. Por tanto, ante un acto inexistente lo único que queda es desconocer totalmente sus consecuencias.

El régimen de los actos inexistentes puede resumirse en tres reglas básicas: a) la inexistencia se produce de pleno derecho; b) el acto inexistente no puede sanearse; y, c) cualquier persona puede alegar la inexistencia de un acto.

La inexistencia se produce de pleno derecho y, por tanto, no es necesaria una sentencia judicial que invalide el acto para privarlo de sus efectos (Vélez, 1924, pág. 374; Valencia \& Ortíz, 2000, pág. 524; Ospina \& Ospina, 2000, pág. 439; Claro, 1979, págs. 582-585; Vodanovic, Tratado de las obligaciones, 2004, pág. 313). En el caso de que las partes le hayan atribuido efectos al acto, cualquier persona puede desconocer esos efectos y destruir las situaciones de hecho, sin necesidad de que preceda una declaratoria judicial de inexistencia (Vélez, 1924, págs. 374376; Valencia \& Ortíz, 2000, págs. 524-525; Ospina \& Ospina,

9 Otros autores, como Valencia \& Ortiz, Ospina \& Ospina, reducen estas causales (Valencia \& Ortiz, 2000, pág. 523; Ospina \& Ospina, 2000, pág. 431). ${ }^{10}$ Cfr. Altabar vs. Salgado, 16 de mayo de 2001, Gaceta Judicial Serie XVII No. 6. 
2000, págs. 339-442; Claro, 1979, págs. 582-585; Vodanovic, De las fuentes de las obligaciones, 1942, pág. 313). Así, por ejemplo, en caso de un contrato de compraventa inexistente en que una de las partes ha tomado posesión de la cosa, el dueño de esa cosa puede intentar la acción reivindicatoria sin necesidad de obtener primero una sentencia judicial que declare que la compraventa no existe jurídicamente.

Por su parte, que el acto inexistente no pueda sanearse significa que ni el paso del tiempo ni la ratificación de las partes pueden hacer que el acto inexistente se tenga por válido.

El paso del tiempo no puede volver existente al acto que nunca llego a configurarse (Ospina \& Ospina, 2000, pág. 313; Vodanovic, 2004, pág. 313). Esto último no excluye que por prescripción adquisitiva se obtenga la consolidación de ciertas circunstancias de hecho; pero, en este caso, el acto no se sanea jamás, sino que las situaciones patrimoniales de hecho se afirman en virtud de la prescripción (Ospina \& Ospina, 2000, pág. 442). Así, por ejemplo, en el caso de un contrato de donación inexistente, el paso del tiempo no podrá hacer que el contrato sea válido, pero por efecto de prescripción se podrá adquirir el dominio de la cosa que se ha tenido en posesión.

Por otro lado, las partes no podrán celebrar un acto de convalidación que le de eficacia retroactiva al acto que no llegó a configurarse (Valencia \& Ortíz, 2000, pág. 525; Ospina \& Ospina, 2000, pág. 442; Vodanovic, 1942, pág. 313). Como es natural, esto no obsta a que las partes celebren un nuevo acto que surta efectos para el futuro (Valencia \& Ortíz, 2000, pág. 525; Ospina \& Ospina, 2000, pág. 441). Así, en el caso del contrato de promesa de compraventa de un inmueble que se celebró mediante instrumento privado, las partes no pueden ratificar el contrato, pero sí pueden celebrar un nuevo contrato por escritura pública que surta efectos para el futuro.

En un interesante fallo que abona el punto sobre la indisponibilidad que las partes tienen sobre un acto inexistente, la 
Corte Nacional de Justicia sostuvo que los contratantes no tiene la potestad de extinguir por mutuo acuerdo un acto inexistente, pues, al no existir el acto primario, el convenio por el cual se lo pretende dejar sin efecto no tendría objeto y sería, él también, inexistente $\mathrm{e}^{11}$.

Finalmente, la inexistencia tiene un efecto erga omnes. Esto significa que cualquier persona, incluso quien celebró el acto sabiendo o debiendo saber que éste carecía de alguno de sus elementos esenciales y era, por tanto, inexistente, está legitimada para invocar la inexistencia de un acto que se pretende oponer. En realidad, la inexistencia es un vicio tan radical que se permite a toda persona, sin excepción, alegar la inexistencia de un acto y beneficiarse de dicha inexistencia (Vélez, 1924, pág. 375; Vodanovic, 2004, pág. 315).

\subsection{La inexistencia en la legislación ecuatoriana}

Los actos jurídicos inexistentes no están sistemáticamente regulados en el Código Civil, ni en ninguna otra norma de derecho privado ecuatoriano. De hecho, ni el Código Civil ni ninguna otra norma de derecho privado en el Ecuador mencionan siquiera las palabras "acto inexistente" 12 . Esto ha creado criterios divididos en la doctrina sobre el reconocimiento de la inexistencia jurídica en nuestro ordenamiento jurídico.

Según una primera opinión, el Código Civil reconoce la institución de los actos inexistentes ${ }^{13}$. Se sostiene que aunque no se contemple una regulación sistematizada en el Código Civil de

${ }^{11}$ Cfr. Yépez vs. Word Vacation Wortion et al., 29 de agosto de 2001, Gaceta Judicial Serie XVII No. 7.

${ }^{12}$ No ocurre lo mismo en derecho público. Así, por ejemplo, el artículo 129 del Estatuto del Régimen Jurídico Administrativo de la Función Ejecutiva.

${ }^{13}$ La mayoría de los autores que se acostumbra citar en las sentencias de casación en el Ecuador son partidarios de esta opinión. Cfr. Vélez (1924, pág. 374), Valencia \& Ortíz (2000, pág. 519 y ss.); Ospina (2000, pág. 431 y ss.), Claro (1979, pág. 580 y ss.). 
los actos inexistentes, ciertas disposiciones del Código permiten concluir muy fácilmente que sí se los reconoce. Así, en primer lugar, el Código Civil distingue en los contratos las cosas que son de su esencia, de su naturaleza y las accidentales, y establece que si faltan las cosas de la esencia, el contrato no surte efecto alguno $^{14}$. En otras disposiciones, el Código se refiere a los elementos esenciales comunes a todos los actos jurídicos y señala, de manera general, que si falta la formalidad en el acto solemne éste no surte ningún efecto ${ }^{15}$ y que para que haya un acto jurídico éste debe tener un objeto ${ }^{16}$. Además, al regular contratos específicos, el Código Civil declara que esos contratos no existen en caso de que no cumplan con sus requisitos esenciales ${ }^{17}$.

Según una segunda opinión, la noción de inexistencia es aceptable en la teoría, pero el Código Civil no la reconoce. Por tanto, sostienen los partidarios de esta opinión, todos los casos en los que los actos no cumplen con sus elementos esenciales se encuadran en el régimen de la nulidad absoluta (Alessandri Besa, 2011, pág. 22). Para sostener esta opinión se argumenta que el

\footnotetext{
${ }^{14}$ Artículo 1460 del Código Civil. La doctrina reiteradamente ha hecho énfasis en la expresión "no surte efecto alguno" que utiliza el artículo.

${ }^{15}$ Especialmente decidor en este sentido es el artículo 1459 que, en su parte pertinente, establece que el contrato "es solemne cuando está sujeto a la observancia de ciertas formalidades especiales, de manera que sin ellas no surte ningún efecto civil". La doctrina ha puesto énfasis en la expresión "no surte ningún efecto civil".

${ }^{16}$ Según el artículo 1476 del Código Civil, "[t]oda declaración de voluntad debe tener por objeto una o más cosas que se trata de dar, hacer o no hacer". Según la doctrina, de este artículo se deduce que si falta el objeto, no existe la declaración de voluntad, esto es, el acto jurídico.

${ }^{17}$ Así, por ejemplo, en la regulación del contrato de compraventa: con respecto a la falta de escritura pública en la venta de bienes raíces, servidumbres y sucesiones hereditarias, el artículo 1740 dice que esas compraventas "no se reputaran perfectas ante la ley"; el artículo 1748 señala que si no se conviene sobre el precio, "no habrá venta"; con respecto a la falta de la cosa que se vende, el artículo 1753 señala que si vende una cosa que no existe, el contrato "no surte efecto alguno".
}

Ius Humani, v. 2 (2010/11), p. 184 
Código Civil en ningún lugar dice que un acto pueda ser tenido por inexistente, y que el Título XX del Código, que es el único título dedicado a regular la sanción de ineficacia de los actos jurídicos, sólo habla de nulidad absoluta y de nulidad relativa, pero no de inexistencia. Además, los partidarios de esta opinión señalan que los incapaces absolutos no tienen voluntad y que, a pesar de eso, sus actos son sancionados por el Código Civil con la nulidad absoluta y no con la inexistencia ${ }^{18}$.

Sobre el punto, la jurisprudencia ecuatoriana no es uniforme. En algunos fallos, la Corte Nacional de Justicia ha declarado nulos absolutamente a los actos a los que les falta alguno de sus requisitos esenciales y ha dicho que la inexistencia no tiene cabida en el derecho privado ecuatoriano ${ }^{19}$. Mientras tanto, en otros fallos la Corte ha señalado que los actos que carecen de sus requisitos esenciales deben ser tenidos por inexistentes y que no es necesaria que sea declarada su ineficacia para que sean desconocidos sus efectos ${ }^{20}$.

Por nuestra parte, pensamos que el fundamento jurídico de la inexistencia en el derecho ecuatoriano está en el concepto de lo esencial. La esencia es lo que constituye la naturaleza de las cosas, lo que hace que una cosa sea lo que es: si falta la esencia, la cosa

${ }^{18}$ En efecto, el artículo 1698 del Código Civil en su parte pertinente establece que "[h]ay asimismo nulidad absoluta en los actos y contratos de personas absolutamente incapaces".

${ }^{19}$ Aguilar vs. Servicio Hotelero, 8 de febrero de 2001, Gaceta Judicial Serie XVII No. 4; Torres vs. Sánchez et al., 23 de septiembre de 2002, Gaceta Judicial Serie XVII No. 10. Curiosamente en estos dos casos, en primera y segunda instancia se dijo que el contrato era inexistente, pero en casación se lo declaró nulo absolutamente. Cooperativa Vivienda Los Chasquis vs. Aseguradora del Sur, 8 de diciembre de 2009, Gaceta Judicial Serie XVIII No. 7.

${ }^{20}$ Rengel vs. Balseca et al., 14 de mayo de 1999, Gaceta Judicial Serie XVII No. 2; Altabar vs. Salgado, 16 de mayo de 2001, Gaceta Judicial Serie XVII No. 6; Yépez vs. Word Vacation Wortion et al., 29 de agosto de 2001, Gaceta Judicial Serie XVII No. 7; Cárdenas vs. Armijos et al., 25 de enero de 2006, Gaceta Judicial Serie XVIII No. 2. 
deja de ser. Por tanto, el derecho ecuatoriano reconoce los actos inexistentes desde el momento en que el Código Civil señala que los contratos tienen elementos que son de su esencia.

Creemos que si el acto inexistente es por definición el que no nace a la vida jurídica, es natural que no tenga una regulación legal. No parece sensato esperar que se regule lo que no existe. La falta de regulación legislativa se explica si se considera que la inexistencia no es propiamente una sanción -como veremos que sí lo es la nulidad-, sino, más sencillamente, una consecuencia jurídica de no cumplir con requisitos legales mínimos. Por eso, que no haya una regulación sistemática de la inexistencia en la ley no obsta para reconocer la inexistencia en nuestro derecho.

\subsection{El acto putativo}

Hay casos en los que un acto jurídico, a pesar de no cumplir con sus requisitos esenciales o de validez, aparenta existir y ser válido. Un sector de la doctrina se refiere especialmente a estos actos como "actos putativos" 21 .

El Código Civil utiliza la palabra "putativo" para referirse al matrimonio que, a pesar de ser nulo, aparenta ser válido; y, para referirse al heredero que no lo es, pero que aparenta serlo. Cuando las situaciones son aparentes, como si el matrimonio fue celebrado con las solemnidades o si una providencia judicial concede la posesión efectiva al que no es heredero, el Código manda a respetar los efectos civiles de la situación hasta tanto no se declare su ineficacia ${ }^{22}$. Creemos que estos dos casos contemplados en el Código Civil recogen un principio de respeto a las apariencias, que puede ser extendido por analogía a todos los actos jurídicos en derecho privado, y que justifica la referencia a una categoría especial de actos imperfectos denominada "actos putativos".

${ }^{21}$ Cfr. Ospina \& Ospina (2000, pág. 428 y ss.), donde los autores reconocen que otra forma de denominar estos actos es la de "actos aparentes".

${ }^{22}$ En este sentido, cfr. los artículos 24, 94, 212, 719 y 1292 del Código Civil.

Ius Humani, v. 2 (2010/11), p. 186 
Para que un acto se considere putativo, debe aparentar existir y ser válido desde la perspectiva de una persona que obra con mediana diligencia. En términos jurídicos, la apariencia supone el convencimiento de que una situación irregular está conforme a derecho, cuando tal convencimiento se deriva de un error excusable, es decir, exento de culpa ${ }^{23}$. Ejemplo de acto putativo es el contrato de compraventa de inmueble hecho por escritura pública, pero que es absolutamente simulado. En tal caso el acto es técnicamente inexistente porque falta la voluntad de las partes, pero un tercero que revisa la escritura pública tiene una fundada razón para creer que el acto es válido.

El acto jurídico putativo produce la plenitud de sus efectos hasta que una sentencia declare su inexistencia o invalidez

${ }^{23} \mathrm{El}$ acto putativo es una consecuencia de la teoría de la apariencia y, por tanto, del principio de buena fe. Según el desarrollo doctrinario, para que la teoría de la apariencia aplique se necesita que quien la invoque esté de buena fe. La buena fe a la que nos referimos aquí es la buena fe "subjetiva", esto es, la creencia de obrar de acuerdo a derecho. Según la corriente doctrinaria mayoritaria, para que haya buena fe subjetiva debe obrarse diligentemente. Por tanto, la buena fe es más que una simple creencia, sino que se trata de una creencia fundada. Esto encuentra soporte legal en el artículo 721 del Código Civil que, en su parte pertinente, señala que "[e]l justo error, en materia de hecho, no se opone a la buena fe"; una interpretación contrariu sensu nos lleva a la conclusión de que el "error injusto", el que se comete por no obrar con diligencia, sí se opone a la buena fe. La diligencia, según la regla general del artículo 29 del Código Civil, se aprecia in abstracto, esto es, considerando un modelo ideal de persona, "el padre de familia", y sin atender a las condiciones especiales y concretas de la persona. Guzmán hace un desarrollo especialmente lúcido sobre la buena fe en el Código Civil (2002, págs. 11-23). En el sentido de que para determinar la buena fe subjetiva debe utilizarse un modelo abstracto de diligencia (Valencia, 1979, pág. 348). En un fallo especialmente interesante, en donde la Corte Nacional de Justicia analizó la nulidad de un contrato de derecho público, se sostuvo que la buena fe está reñida con la negligencia, y se utilizó un estándar abstracto u objetivo para determinar que había negligencia y que, por tanto, no se obraba de buena fe: Procurador General de la Nación vs. Fundación para la Educación y el Desarrollo, 15 de mayo de 1980, Gaceta Judicial Serie XIII No. 8. 
(Ospina \& Ospina, 2000, pág. 429). Esto es así porque, como tradicionalmente ha estado implícito en el Código Civil y en la legislación de derecho privado, las situaciones aparentemente normales deben respetarse hasta que no se declare judicialmente lo contrario. En el fondo, lo que ocurre es que se vuelve imperativo el respeto momentáneo a actos jurídicos imperfectos cuando de ese respeto depende la legítima situación de un tercero de buena fe. Como ha dicho la Corte Nacional de Justicia, "el error común constituye derecho" 24 .

Como se ve, puede darse el caso de que un acto sea jurídicamente inexistente pero que, ante los ojos de una persona razonable, aparezca como válido. En tal caso se estará ante un acto jurídico putativo que se tendrá por válido y surtirá sus efectos hasta tanto no sea declarado inexistente por una sentencia judicial. Por tanto, el acto putativo constituye una excepción al principio de que la inexistencia se produce de pleno derecho (Ospina \& Ospina, 2000, pág. 440). En realidad ésta es la importancia práctica del acto putativo: permite explicar por qué hay actos que aún cuando carecen de alguno de sus requisitos esenciales, requieren de declaración judicial para ser tenidos por ineficaces.

No sabemos de caso alguno en que la Corte Nacional de Justicia haya acogido la doctrina de los actos putativos. Sin embargo, parece que la aplicación de esta teoría podría ser una herramienta muy útil para otorgar una legítima protección a

\footnotetext{
${ }^{24}$ Mirsky vs. Maquínez, 17 de diciembre de 2003, Gaceta Judicial Serie XVII No. 14. Según se ha dicho, el aforismo de que el error común constituye derecho, error communis facit ius, viene desde los romanos y está establecido en el Digesto. Como se cuenta, la máxima tuvo su origen en un hecho algo peculiar: un esclavo llamado Barbacio Filipo fue nombrado cuestor propretor. En Roma estaba prohibido que un esclavo ejerciera tales funciones. Cuando se conoció su inhabilidad, debieron haberse declarado inexistentes todas sus resoluciones, pero tal cosa habría perturbado gravemente el desarrollo de la vida jurídica, por lo que decidió dejarlas en firme, aunque Barbacio fue quemado vivo por haber inducido a error (Vodanovic, 2004, pág. 49).
}

Ius Humani, v. 2 (2010/11), p. 188 
sujetos de derecho perjudicados por un acto que aunque jurídicamente no existe, aparenta ser válido.

\section{Nulidad AbSOluta}

\subsection{Inexistencia y nulidad}

El derecho protege los efectos de un acto jurídico bajo el entendido de que dicho acto exista y sea válido. Hemos visto cuando un acto jurídico es inexistente y ahora nos referiremos al acto jurídico que, existiendo, no es válido.

Son dos cosas distintas la existencia y la validez. Un acto existe cuando cumple sus requisitos esenciales. Un acto es válido cuando cumple sus requisitos de validez. Los requisitos esenciales son los presupuestos mínimos que debe cumplir un acto para perfeccionarse. Los requisitos de validez suponen la existencia del acto y son establecidos por la ley para impedir que ese acto afecte al interés general de la sociedad o al interés particular de quienes celebran el acto. Lo dicho aquí se ilustra considerando que una cosa es que un contrato de depósito no tenga objeto, en cuyo caso el contrato es inexistente, y otra cosa distinta es que tenga por objeto almacenar armas nucleares, en cuyo caso el contrato existe, por tener objeto, pero no es válido, porque su objeto atenta contra el interés general de la sociedad.

Por regla general, frente a un acto inexistente la ley manda a desconocer sus efectos sin necesidad de que un juez declare su ineficacia. Frente a un acto inválido, en cambio, la ley manda a respetar sus efectos hasta que un juez declare expresamente su nulidad.

Así, la inexistencia y la nulidad son dos categorías distintas, con diferentes fundamentos y con diferentes consecuencias. En el primer caso el acto nunca llegó a configurarse, en el segundo caso el acto se ha configurado pero de manera viciada. 
Recalcando la diferencia la inexistencia y la nulidad de un acto jurídico, la Corte Nacional de Justicia ha dicho que hay incompatibilidad de acciones $\mathrm{y}$, por tanto, debe desecharse la demanda, si el actor solicita que se tenga por inexistente un acto y, al mismo tiempo, que se declare su nulidad ${ }^{25}$.

\subsection{La nulidad absoluta}

La nulidad ha sido entendida por nuestra Corte Nacional de Justicia como una sanción consistente en privar de efectos al acto $^{26}$. De la característica de sanción que tiene la nulidad se deriva que las reglas que la regulan son de orden público, por lo que no puede ser derogadas por las partes (Vodanovic, 1961, pág. 322); y, que, dado que las sanciones deben interpretarse restrictivamente, la nulidad ni puede aplicarse por analogía ${ }^{27}$, ni puede aplicarse al acto que no viola un requisito de validez establecido legalmente, sino cualquier otro tipo de requisito, por más importante que se le considere (Vodanovic, 1961, págs. 322323; Alessandri Besa, 2011, pág. 30 ${ }^{28}$.

El Código Civil distingue entre nulidad absoluta y nulidad relativa. Según ha destacado la jurisprudencia y la doctrina, esta distinción atiende al tipo de requisito de validez que el acto no cumple. La nulidad absoluta supone un grado de imperfección más grave que la nulidad relativa, precisamente porque los

${ }^{25}$ En este sentido, cfr. Borja vs. Campos et al, 8 de mayo de 1997, Gaceta Judicial, Serie XVI, No. 9.

${ }^{26}$ Cfr. Calle et al. vs. Muñoz et al., 5 de febrero de 2002, Gaceta Judicial, Serie XVII, No. 8.

${ }^{27}$ Wong et al. vs. Banco Bolivariano, 6 de mayo de 2004, Gaceta Judicial Serie XVII No. 14.

${ }^{28}$ Es interesante hacer notar que para Alessandri si se viola un requisito de validez establecido por reglamento y no por la ley, no hay nulidad, porque ésta sólo entra en acción en caso de que se violen requisitos de validez establecidos legalmente (Alessandri Besa, 2011, pág. 78). En este sentido la Corte Nacional de Justicia: Calle et al. vs. Muñoz et al., 5 de febrero de 2002, Gaceta Judicial Serie XVII No. 8.

Ius Humani, v. 2 (2010/11), p. 190 
requisitos de validez violados son más graves (Ospina \& Ospina, 2000, pág. 447; Vodanovic, 1961, pág. 322; Alessandri Besa, 2011, pág. 21). La nulidad absoluta ha sido establecida en consideración al interés general o al orden público, y la nulidad relativa ha sido establecida en consideración al interés particular de las personas que celebran el acto (Vélez, 1924, pág. 376; Alessandri Besa, 2011, págs. 100-101) ${ }^{29}$. Se trata de dos acciones diferentes $\mathrm{y}$, en concordancia con esto, la Corte Nacional de Justicia, ha dicho que no hay cosa juzgada porque no hay identidad objetiva si en un juicio se demanda la nulidad absoluta de un contrato y en otro se pide la nulidad relativa del mismo contrato $^{30}$.

La nulidad absoluta es la sanción que la ley impone a los actos que carecen de un requisito de validez que ha sido establecido con el fin de proteger el interés general ${ }^{31}$. Se trata de un mecanismo previsto por la ley para que los actos jurídicos no afecten a los intereses sociales. El término "absoluta" no se refiere a la intensidad con que se aplica la sanción de ineficacia, sino a la protección general que este tipo de nulidad persigue (Vodanovic, 1961, pág. 322; Alessandri Besa, 2011, pág. 129).

\subsection{Causales de nulidad absoluta}

El Código Civil señala taxativamente los casos en los que cabe la sanción de nulidad absoluta. Se trata de casos en los que está involucrado el interés general de la sociedad. Así, la nulidad

\footnotetext{
29 Algo escépticos de que ésta haya sido efectivamente la motivación del legislador para clasificar la nulidad en absoluta y relativa se muestran ciertos autores (Valencia \& Ortiz, 2000, pág. 525; Ospina \& Ospina, 2000, págs. 447448).

${ }^{30}$ Cfr. Solís vs. Aguilar et al., 14 de octubre de 2004, Gaceta Judicial Serie XVIII No. 1.

${ }^{31}$ Freire vs. Narváez et al, 21 de octubre, Gaceta Judicial Serie XVII No. 2. En el mismo sentido, Alessandri Besa (2011, pág. 131).
} 
absoluta se produce: a) cuando el objeto del acto es ilícito; b) cuando la causa del acto es ilícita; c) cuando se omite alguna formalidad establecida en consideración de la naturaleza del acto; $\mathrm{y}$, d) cuando el acto es realizado por personas absolutamente incapaces $^{32}$.

El régimen de la nulidad absoluta es de excepción y, por tanto, los casos en los que procede deben ser interpretados restrictivamente (Valencia \& Ortíz, 2000, pág. 525).

\subsubsection{Objeto ilícito}

El concepto de objeto no es claro en el Código Civil (Ospina \& Ospina, 2000, págs. 238-239). Según el criterio doctrinal que nos parece acertado, el objeto de un acto jurídico es la cosa o conducta sobre la que recae la obligación que dicho acto crea (Vodanovic, 1961, págs. 235-236) ${ }^{33}$. Así, por ejemplo, son objetos de un contrato de compraventa la cosa vendida y el precio pagado.

El Código Civil no define lo que debe entenderse por objeto ilícito, sino que se limita a enumerar algunos casos en los que éste se produce. Según el criterio doctrinal que hemos seguido, habrá objeto ilícito cuando la cosa o la conducta sobre la que recae la

${ }^{32}$ Las causales de nulidad absoluta están recogidas en el artículo 1698 del Código Civil. En este sentido, la Corte Nacional de Justicia en: Toledo vs. Sicomesa, 13 de abril de 1998, Gaceta Judicial Serie XVI No. 11; Contraloría General del Estado vs. Municipalidad de Cuenca et al., 18 de marzo de 2003, Gaceta Judicial Serie XVII No. 12.

${ }^{33}$ Este criterio no parece ser compartido por la jurisprudencia ecuatoriana. La Corte Nacional de Justicia ha fallado diciendo que el objeto de un acto es la relación jurídica que el acto crea: Paz et al. vs. Guambaña et al., 28 de julio de 2003, Gaceta Judicial Serie XVII No. 13. Nos hemos separado de esta línea de pensamiento porque creemos que definir el objeto como la cosa sobre la que recae la obligación generada por el acto permite encuadrar dentro del concepto de objeto ilícito los casos en que éste se produce según el Código Civil (cosas fuera del comercio, derechos personalísimos, sucesión futura) y, además, permite separar el concepto de objeto con el de causa de una forma nítida.

Ius Humani, v. 2 (2010/11), p. 192 
obligación que el acto crea sean contrarios al orden público, a las buenas costumbres o a la ley ${ }^{34}$. Así, por ejemplo, habrá objeto ilícito en la venta de armas de destrucción masiva, porque tales armas suponen una amenaza al orden público; en el pacto por el cual un equipo profesional de fútbol se deja ganar un partido a cambio de un pago, porque se trata de una conducta que atenta contra las buenas costumbres; y, en la venta de tierras que la Constitución declara inalienables, porque existe una expresa disposición legal que hace que esos bienes sean incomerciables.

En realidad, la nulidad por objeto ilícito ha sido tratada de una forma especialmente contradictoria por la Corte Nacional de Justicia, al punto que puede concluirse que la jurisprudencia, en vez de brindar luces sobre el alcance y los límites del concepto de objeto ilícito y de la nulidad absoluta como su sanción, confunde y desconcierta al respecto ${ }^{35}$.

\subsubsection{La causa}

El Código Civil define a la causa de un acto como el motivo que induce a las partes a su celebración ${ }^{36}$. La doctrina ha

${ }^{34}$ El Código Civil establece en el artículo 1478 una regla general y vaga: hay objeto ilícito "en todo lo que contraviene al Derecho Público ecuatoriano", y enumera algunos casos de ilicitud de objeto en los artículos siguientes. La doctrina ha sentado la regla de que la ilicitud se produce cuando se viola la ley, el orden público o las buenas costumbres (Vélez, 1924, pág. 383; Ospina \& Ospina, 2000, págs. 448-449; Vodanovic, 1961, pág. 239; Alessandri Besa, 2011, págs. 137-138).

35 Dos casos que aparecen como especialmente desconcertantes son la declaración de nulidad absoluta por objeto ilícito en el caso de que el administrador de una compañía contrate con la compañía que administra, Jaramillo et al. vs. Heredia et al., 26 de marzo de 2001, Gaceta Judicial Serie XVII No. 5, y la declaración de nulidad absoluta en la venta de gananciales sin que haya precedido la partición, Avilés et al. vs. Avilés et al., 22 de febrero de 2001, Gaceta Judicial Serie XVII No. 5.

${ }^{36}$ Artículo 1483 del Código Civil. No es el criterio de la Corte Nacional de Justicia, que ha dicho que no es lo mismo el motivo que la causa: Jaramillo et 
destacado que esta definición legal supone que nuestro legislador ha tomado abiertamente partido por la teoría subjetiva de la causa (Ospina \& Ospina, 2000, págs. 278-279; Vodanovic, 1961, págs. 254-255) ${ }^{37}$. Por tanto, en nuestro derecho, la causa se refiere a los motivos sicológicos e internos que tienen las partes al contratar. Así, por ejemplo, la causa del contrato de compraventa generalmente será usar según su destino la cosa vendida, en el caso del comprador, y obtener una ganancia económica, en el caso del vendedor; pero esta causa variará de caso en caso, dependiendo de los móviles particulares de las partes en cada acto determinado.

Según señala el Código Civil, hay causa ilícita cuando los motivos que inducen a las partes a celebrar el acto son prohibidos por la ley, contrarios al orden público o a las buenas costumbres ${ }^{38}$. En estos casos, se permite al juez indagar los motivos personales y subjetivos que tuvieron las partes para celebrar el acto, y determinar si esas intenciones son contrarias a la ley, al orden público o a las buenas costumbres (Ospina \& Ospina, 2000, págs. 278-279). Así, por ejemplo, podría declararse la nulidad absoluta de la transacción que se hace en un juicio en que las partes han acordado previamente el juicio como medio para traspasar activos sin pagar impuestos, o, según un caso resuelto por la Corte Nacional de Justicia, a un contrato de compraventa simulado en el que las partes buscan deliberadamente perjudicar a terceros, excluyéndolos de la sucesión hereditaria ${ }^{39}$.

al. vs. Heredia et al., 26 de marzo de 2001, Gaceta Judicial Serie XVII No. 5; Flores vs. Cooperativa de Vivienda Ciudad de Ibarra, 22 de abril de 2002, Gaceta Judicial Serie XVII No. 9.

${ }^{37}$ Como se ha dicho, éste no ha sido el criterio de la Corte Nacional de Justicia: Jaramillo et al. vs. Heredia et al., 26 de marzo de 2001, Gaceta Judicial Serie XVII No. 5; Flores vs. Cooperativa de Vivienda Ciudad de Ibarra, 22 de abril de 2002, Gaceta Judicial Serie XVII No. 9.

${ }^{38}$ Artículo 1483 del Código Civil.

${ }^{39}$ Cfr. Avilés et al. vs. Avilés et al., 22 de febrero de 2001, Gaceta Judicial Serie XVII No. 5.

Ius Humani, v. 2 (2010/11), p. 194 
Así entendida, la causa ilícita como razón para declarar la nulidad absoluta de un acto aplicará a casos en los que la prestación aisladamente considerada no sea ilícita, pero sí lo sea la finalidad que se persigue con el acto.

\subsubsection{El defecto en la solemnidad}

Además del objeto ilícito y de la causa ilícita, es causal de nulidad absoluta la deficiencia de forma en los actos solemnes. En este caso, la nulidad absoluta se produce porque, tratándose de actos para cuya celebración es necesaria una solemnidad, dicha solemnidad existiendo, adolece de algún defecto.

La forma solemne es un requisito esencial del acto jurídico y su falta no produce la nulidad absoluta sino la inexistencia (Valencia \& Ortíz, 2000, págs. 523-524; Claro, 1979, pág. 599) ${ }^{40}$. Por eso, una doctrina consistente con la teoría de la inexistencia señala que la falta de formalidad que sanciona el Código Civil con nulidad absoluta no es la inobservancia total de la solemnidad, sino la omisión de los requisitos legales prescritos para la solemnidad. Según la explicación, si se contrata por escritura privada la compraventa de un inmueble, el contrato es inexistente; en cambio, si se contrata por escritura pública, pero la escritura carece de las firmas de las partes, que es un requisito legal establecido para el valor de la escritura, el contrato es nulo absolutamente (Ospina \& Ospina, 2000, pág. 551) ${ }^{41}$.

Por otro lado, según lo ha destacado la Corte Nacional de Justicia, el hecho de que se celebre un acto con una solemnidad formal, no hace que el acto se convalide si adolece de algún otro

${ }^{40}$ En contra están Vodanovic (1961, pág. 324) y Alessandri Besa (2011, pág. 263 y ss.).

${ }^{41} \mathrm{La}$ Corte Nacional de Justicia declaró que era inexistente, y no solamente nula, la escritura pública en la que faltaba las firmas de notarios y testigos: Maurillo vs. Assaf, 21 de noviembre de 1996, Gaceta Judicial Serie XVI No. 7. En este caso, en realidad, la falta de firma del notario es equivalente a que no se haya otorgado ninguna escritura pública. 
vicio que lo invalida ${ }^{42}$. Por tanto, si bien el vicio en la solemnidad tendrá como resultado seguro la nulidad absoluta del acto, a la inversa no funciona igual, y el acto celebrado cumpliendo la solemnidad pertinente sin ningún defecto, puede ser nulo por alguna otra causal. En definitiva, la solemnidad no sirve para purgar de defecto al acto que adolece de nulidad.

\subsubsection{Actos de los absolutamente incapaces}

Finalmente, también hay nulidad absoluta en los actos que son celebrados por los absolutamente incapaces. El Código Civil prescribe que son absolutamente incapaces los menores impúberes, los dementes y los sordomudos que no se pueden dar a entender por escrito ${ }^{43}$.

Según una doctrina consistente con la teoría de la inexistencia, los absolutamente incapaces no carecen totalmente de voluntad, sino que tienen una muy precaria. Por eso, sus actos no son inexistentes sino que están viciados con nulidad absoluta (Claro, 1979, págs. 600-601).

Los casos más frecuentes de nulidad de actos celebrados por incapaces absolutos se refieren a los actos de los dementes. Según ha dicho la Corte Nacional de Justicia, el Código Civil utiliza la palabra "demente" para referirse a aquella persona adulta que adolece de un grave trastorno en la mente ${ }^{44}$. En caso de que el demente haya sido declarado en interdicción al momento de celebrar el acto, existe una presunción de derecho de que la persona era demente y su acto adolece, siempre, de nulidad

\footnotetext{
${ }^{42}$ Cfr. Chela vs. Rea, 11 de diciembre de 1996, Gaceta Judicial Serie XVI No. 7.

${ }^{43}$ Artículo 1463 del Código Civil.

${ }^{44}$ Cfr. Cadena vs. Jaramillo, 29 de marzo de 1999, Gaceta Judicial Serie XVI No. 15. En este mismo fallo, además, la Corte Nacional sostuvo el criterio de que no se hayan comprendidos en la expresión "dementes" los sonámbulos, los ebrios $\mathrm{y}$, en general, aquellos que están privados de la razón sólo momentáneamente.
} 
absoluta $^{45}$. Por otra parte, si tal interdicción no ha sido declarada judicialmente, la perturbación de las facultades al tiempo de suscribir el acto, debe probarse de forma inconcusa, evidente, concluyente $^{46}$, y, en caso de que exista esta prueba, el acto adolecerá de nulidad absoluta.

\subsection{Legitimación para solicitar la nulidad absoluta}

Debido a la naturaleza de los fines que protege la nulidad absoluta, el Código Civil reconoce una amplia legitimación activa para solicitar su declaración judicial ${ }^{47}$.

En primer lugar, el Código señala que puede solicitar la nulidad absoluta todo aquel que tenga un interés en ello. La Corte Nacional de Justicia y la doctrina coinciden en que el interés al que se refiere el Código Civil es un interés de carácter pecuniario $^{48}$. Por tanto, todo aquel que obtenga un beneficio patrimonial en que el acto sea declarado ineficaz, está legitimado en solicitar su nulidad absoluta, sea que este beneficio consista en un aumento del activo o en una reducción del pasivo de su patrimonio. Así, por ejemplo, el acreedor de la parte que ha enajenado un bien inmueble en virtud de un contrato de compraventa viciado con nulidad absoluta, puede solicitar la nulidad de ese contrato pues tiene un interés en que el bien siga en poder de su deudor para poder cobrar su deuda. Como ha destacado la Corte Nacional de Justicia, que el Código Civil

${ }^{45}$ Cfr. Cadena vs. Jaramillo, 29 de marzo de 1999, Gaceta Judicial Serie XVI No. 15.

${ }^{46}$ Cfr. Ponce vs. Fundación Amigos del Ecuador, 31 de octubre de 1995. Gaceta Judicial Serie XVI No. 4; Delgado et al. vs. Guerrón, 27 de junio de 1996, Gaceta Judicial Serie XVI No. 6; y, Cadena vs. Jaramillo, 29 de marzo de 1999, Gaceta Judicial Serie XVI No. 15.

${ }^{47}$ El Código Civil establece la legitimación para solicitar que se declare la nulidad absoluta en el artículo 1699.

${ }^{48}$ Cfr. Jaramillo et al. vs. Heredia et al., 26 de marzo de 2001, Gaceta Judicial Serie XVII No. 5. Cfr. Ospina (2000, pág. 454), Claro (1979, págs. 605-606), Vodanovic (1961, pág. 325) y Alessandri Besa (2011, pág. 524). 
otorgue legitimidad para solicitar la nulidad absoluta a todo quien tenga interés en ello, no significa que otorgue acción popular y, por tanto, el interés debe existir y probarse ${ }^{49}$.

El Código Civil, inspirado en el principio de buena fe y en la prohibición de aprovecharse de la propia culpa ${ }^{50}$, establece una excepción a la regla de que todo interesado puede solicitar la nulidad absoluta, diciendo que se prohíbe solicitar la nulidad a quien celebra o ejecuta el acto sabiendo o debiendo saber el vicio que lo invalidaba ${ }^{51}$. El conocimiento del vicio que prescribe la ley no se refiere a la presunción general de conocimiento de la ley, sino que se trata de un conocimiento específico que debe ser establecido de manera concreta, pues, en caso contrario, jamás podría una de las partes solicitar la nulidad absoluta (Vodanovic, 1961, págs. 325-326) ${ }^{52}$. Así, no puede solicitar la nulidad de un contrato de sicariato el que pagó a otro para que asesine, pues todo el mundo sabe que tal contrato tiene objeto ilícito; pero sí puede solicitar la nulidad de un contrato de provisión de un medicamento cuya comercialización está prohibida en el Ecuador la compañía farmacéutica extranjera que no sabía ni debía saber que aquel constituye objeto ilícito en el Ecuador por ser incomerciable en virtud de una resolución de la Corte Constitucional.

${ }^{49}$ Cfr. Contraloría General del Estado vs. Municipalidad de Cuenca et al., 18 de marzo de 2003, Gaceta Judicial Serie XVII No. 12

${ }^{50}$ La doctrina ha recalcado que esta excepción es una consecuencia de la máxima nemo auditur propriam turpitudinem allegans (Ospina \& Ospina, 2000, pág. 524; Vodanovic, 1961, pág. 325; Alessandri Besa, 2011, pág. 560).

${ }^{51}$ Aguilar vs. Servicio Hotelero, 8 de febrero de 2001, Gaceta Judicial Serie XVII No. 4; Ulloa et al. vs. Filanbanco et al., 21 de junio de 2002, Gaceta Judicial Serie XVII No. 10; Layedra vs. Fuenmayor et al., 9 de abril de 2007, Gaceta Judicial Serie XVIII No. 5. A favor de que el mandante puede solicitar la nulidad se expresa Claro (1979, pág. 610). Un completo desarrollo del tema en Alessandri (2011, págs. 567-580).

${ }^{52}$ En este sentido, la Corte Nacional de Justicia: Jaramillo et al. vs. Heredia et al., 26 de marzo de 2001, Gaceta Judicial Serie XVII No. 5.

Ius Humani, v. 2 (2010/11), p. 198 
Sobre esta prohibición de alegar la nulidad, la Corte Nacional de Justicia ha llegado a dos conclusiones muy discutibles. En primer lugar, ha dicho que no puede alegar la nulidad el mandante por el acto celebrado por el mandatario que sabía o debía saber el vicio ${ }^{53}$. En segundo lugar, ha sentado la innovadora doctrina de que la prohibición de solicitar la nulidad absoluta a quien conoció o debió conocer el vicio, no aplica cuando se trata de vicios que afectan el orden público, las buenas costumbres y la inviolabilidad de las instituciones ${ }^{54}$, llegando a sostener, incluso, que esto significa que la prohibición de alegar la nulidad por parte de quien celebró el acto sabiendo o debiendo saber que era inválido aplica exclusivamente a contratos entre particulares y no cuando una de las partes es una institución pública $^{55}$.

El Código Civil establece que el juez puede y debe declarar de oficio la nulidad absoluta de un acto cuando el vicio que lo invalida aparece de manifiesto ${ }^{56}$. Es una regla que contradice el principio de justicia rogada que informa al derecho privado en el Ecuador, pero que se justifica por el fin de preservación del interés general que tutela la nulidad absoluta (Ospina \& Ospina, 2000, pág. 452; Claro, 1979, pág. 604; Vodanovic, 1961, pág. 324; Alessandri Besa, 2011, pág. 485).

${ }^{53}$ Cfr. Mejía vs. Mejía et al., 28 de enero de 2003, Serie XVII No. 12; Cooperativa Vivienda Los Chasquis vs. Aseguradora del Sur, 8 de diciembre de 2009, Gaceta Judicial Serie XVIII No. 7. La doctrina parece manifestarse en el sentido contrario. A favor de que el mandante puede solicitar la nulidad se expresa Claro (1979, pág. 610). Un completo desarrollo del tema en Alessandri Besa (2011, págs. 567-580).

${ }^{54}$ Cfr. Maza et al vs. Guamán, 25 de julio de 1998, Gaceta Judicial Serie XVI No. 12.

${ }^{55}$ Municipio de Quito vs. Desaci, 28 de octubre de 1999, Gaceta Judicial Serie XVII No. 2.

${ }^{56} \mathrm{La}$ doctrina destaca que no se trata sólo de una potestad sino de un deber del juez (Ospina \& Ospina, 2000, pág. 452; Alessandri Besa, 2011, pág. 485). 
Deben cumplirse dos requisitos para que el juez pueda y deba declarar de oficio la nulidad absoluta de un acto jurídico: que el acto haya sido introducido al proceso judicial, y que el vicio del acto aparezca de manifiesto (Claro, 1979, pág. 604; Vodanovic, 1961, pág. 324; Alessandri Besa, 2011, págs. 486-499) ${ }^{57}$. El acto debe haber sido legalmente introducido al proceso pues no le es permitido al juez decidir sobre un asunto que no ha sido puesto en su conocimiento (Ospina \& Ospina, 2000, pág. 453; Claro, 1979, pág. 604; Alessandri Besa, 2011, págs. 494-495). Además, el vicio debe aparecer de manifiesto, lo que significa que el vicio sea patente en el mismo acto jurídico, sin que haya necesidad de recurrir a otros elementos probatorios ${ }^{58}$. Así, por ejemplo, aparece de manifiesto que un contrato de compraventa es nulo por objeto ilícito si en la escritura pública se dice que se está vendiendo un parque público; pero no aparece de manifiesto el vicio en el caso de la compraventa que se hace sobre un bien que tiene una prohibición de enajenar, si ésta no está anotada al margen de la escritura.

Finalmente, el Código otorga legitimación activa para solicitar la nulidad absoluta al Ministerio Público. En nuestro país, el Ministerio Público está constituido por el Ministerio Fiscal y

\footnotetext{
${ }^{57}$ Citando una sentencia colombiana, Valencia \& Ortiz añaden a estos dos requisitos, que concurran las partes que celebraron el acto (2000, pág. 526). Una explicación a propósito de este requisito en Alessandri Besa (2011, págs. 493-494). Recientemente, la Corte Nacional de Justicia sostuvo que aunque el vicio aparezca de manifiesto y el acto haya sido introducido al juicio, no procede declarar la nulidad de oficio si de ello se sigue un beneficio para la parte que solicitó la nulidad, pues aquello atentaría contra la buena fe, Cooperativa Vivienda Los Chasquis vs. Aseguradora del Sur, 8 de diciembre de 2009, Gaceta Judicial Serie XVIII No. 9.

${ }^{58}$ Cfr. Aguilar vs. Servicio Hotelero, 8 de febrero de 2001, Gaceta Judicial Serie XVII No. 4. La doctrina es unánime en este tema (Vélez, 1924, pág. 397; Valencia \& Ortiz, 2000, pág. 526; Claro, 1979, pág. 604; Vodanovic, 1961, pág. 324; Alessandri Besa, 2011).
}

Ius Humani, v. 2 (2010/11), p. 200 
sus agentes y, además, según ha dicho la Corte Nacional de Justicia, por la Procuraduría General del Estado ${ }^{59}$.

El Ministerio Público puede solicitar la nulidad de un acto en el sólo interés de la moral. Por tanto, en este caso no se aplica la prohibición de quien celebra o ejecuta el acto sabiendo o debiendo saber el vicio, ni tampoco la limitación de que el vicio de nulidad aparezca de manifiesto en el acto. Así, es factible que en un caso en que a una de las partes le esté vedado solicitar la nulidad absoluta por haber sabido o haber debido saber el vicio, y en el que el juez no pueda declarar la nulidad de oficio por no aparecer de manifiesto en el acto, el Ministerio Público esté legitimado para solicitar la nulidad en el interés de la moral (Alessandri Besa, 2011, pág. 517).

\subsection{Saneamiento y prescripción de la nulidad absoluta}

El Código Civil ${ }^{60}$ prohíbe la ratificación de un acto que adolece de nulidad absoluta (Ospina \& Ospina, 2000, págs. 455457; Claro, 1979, pág. 611; Vodanovic, 1961, pág. 327; Alessandri Besa, 2011, págs. 482-483). Esto es una consecuencia, en primer lugar, de que el orden público está fuera del alcance de la autonomía de la voluntad (Claro, 1979, pág. 611; Vodanovic, 1961, pág. 327; Alessandri Besa, 2011, pág. 483). Así, las partes no podrían ratificar un contrato de depósito de cocaína, porque no está en su poder negar el carácter de objeto ilícito que estas sustancias estupefacientes tienen en el Ecuador. En segundo lugar, la prohibición de ratificar la nulidad absoluta es una consecuencia de que el Código Civil otorgue legitimación a varias personas para alegarla, porque la ratificación de una de esas personas supondría

\footnotetext{
${ }^{59}$ Cfr. Mejía vs. Mejía et al., 28 de enero de 2003, Serie XVII No. 12.

${ }^{60}$ Artículo 1699 del Código Civil. El Código Civil colombiano difiere en este punto del Código ecuatoriano, pues permite a las partes convalidar un acto nulo absolutamente, siempre que la nulidad absoluta no se produzca por objeto o causa ilícita.
} 
la renuncia al derecho ajeno de otra persona que ya no podría alegar la nulidad (Vodanovic, 1961, pág. 327; Alessandri Besa, 2011, pág. 483). Así, por ejemplo, si se permitiera a las partes ratificar un contrato de compraventa con causa ilícita, después el acreedor de una de esas partes no podría alegar la nulidad absoluta a pesar de tener un interés en ello.

Puede darse el caso de que la causal por la cual un acto adolece de nulidad absoluta deje de ser un impedimento para la validez del acto. Así, por ejemplo, si una mercadería que constituía objeto ilícito al momento de contratar es declarada comerciable por una nueva ley, como si se permite la venta de drogas; o si el absolutamente incapaz se vuelve capaz, como si el demente se sana y deja de estar en interdicción. Aún en estos casos, las partes no están facultadas para ratificar el acto que originalmente es nulo ${ }^{61}$. Las partes podrán celebrar un nuevo acto, pero éste sólo tendrá efectos para el futuro.

Según el tenor literal del Código Civil, un acto nulo absolutamente queda saneado por el paso del tiempo ${ }^{62}$. La ley, una vez transcurrido el plazo de quince años desde que se celebró el acto, considera que el vicio que invalidaba el acto con nulidad absoluta ha desaparecido; el acto se ve como si hubiera sido válido desde un principio (Ospina \& Ospina, 2000, pág. 458; Vodanovic, 1961, pág. 458; Alessandri Besa, 2011, pág. 211) ${ }^{63}$. Según ha observado la doctrina, la nulidad absoluta no debería

${ }^{61}$ Esto es una consecuencia de que "[1]a celebración de un acto jurídico es algo unitario e indivisible, que no puede fraccionarse; por eso, en dicha celebración deben concurrir, a un tiempo, las diversas condiciones que la ley exige para que dicho acto o contrato tenga plena eficacia jurídica" (Alessandri Besa, 2011, pág. 123).

62 Artículo 1699 del Código Civil. Varios autores lo expresan (Ospina \& Ospina, 2000, pág. 458; Claro, 1979, pág. 611; Vodanovic, 1961, pág. 327; Alessandri Besa, 2011, pág. 483).

${ }^{63}$ En contra Fernando Vélez quien, poniendo el ejemplo de un contrato con objeto ilícito, sostiene que el acto nulo absolutamente no puede sanearse jamás (1924, pág. 401).

Ius Humani, v. 2 (2010/11), p. 202 
sanearse nunca pues quod nullum est, nullo lapso temporis convalecere potest, sino que sólo se debería permitir la prescripción adquisitiva extraordinaria de las situaciones de hecho (Vodanovic, 1961, págs. 327-328; Alessandri Besa, 2011, pág. $214)^{64}$.

${ }^{64}$ Especialmente ácidos en la crítica son Ospina \& Ospina (2000, págs. 458459). 


\section{REFERENCIAS}

Abeliuk, R. (2001). Las Obligaciones. Bogotá: Temis y Editorial Jurídica de Chile.

Aguilar vs. Servicios Hoteleros (8 de febrero de 2000).

Alessandri B., A. (2011). La nulidad y la rescisión en el derecho civil chileno. Santiago de Chile: Editorial Jurídica de Chile.

Alessandri R., A. (1942). De la responsabilidad extracontractual en el Derecho civil chileno. Santiago de Chile: Imprenta Universitaria.

Betti, E. (2008). Teoría General del negocio Jurídico. Granada: Comares.

Bustos, J. (1999). La doctrina de la apariencia jurídica. Madrid: Dykinson.

Claro, L. (1979). Explicaciones de derecho civil y comparado. Santiago de Chile: Editorial Jurídica de Chile.

Couture, E. (2009). Fundamentos del Derecho Procesal Civil. Buenos Aires: B de F.

De Castro y Bravo, F. (2002). El negocio jurídico. Madrid: Civitas.

Devis, H. (2009). Nociones generales de derecho procesal civil. Bogotá: Temis.

Galgano, F. (1992). El negocio jurídico. Valencia: Tirant lo Blanch.

Guzmán, A. (2002). La Buena Fe en el Código Civil de Chile. Revista Chilena de Derecho, 29(1), 11-23.

Larrea, J., \& Merino, R. (2004). Derecho civil del Ecuador, vol. XI. Quito: Corporación de Estudios y Publicaciones.

Meza, R. (1974). De las obligaciones. Santiago de Chile: Editorial Jurídica de Chile.

Ospina, G., \& Ospina, E. (2000). Teoría general del contrato y del negocio jurídico. Bogotá: Temis.

Pothier, R. (2007). Tratado de las obligaciones. Buenos Aires: Heliasta.

Valencia, A. (1979). La posesión. Bogotá: Temis. 
Valencia, A., \& Ortíz, Á. (2000). Derecho civil parte general y personas. Bogotá: Temis.

Vélez, F. (1924). Estudios sobre el Derecho civil colombiano, tomo VI (2 ed.). París: Imprenta París-América.

Vodanovic, A. (1942). De las fuentes de las obligaciones. Santiago de Chile: Nascimento.

Vodanovic, A. (1961). Curso de Derecho Civil Parte General. Santiago de Chile: Nascimento.

Vodanovic, A. (2004). Tratado de las obligaciones. Santiago de Chile: Editorial Jurídica de Chile.

\section{Sentencias revisadas}

Aguilar vs. Servicios Hoteleros, 8 de febrero de 2001, Gaceta Judicial Serie XVII No. 4.

ALTABAR vs. Salgado, 16 de mayo de 2001, Gaceta Judicial Serie XVII No. 6 Arévalo et al. vs. Arévalo et al., 4 de junio de 2004, Gaceta Judicial Serie XVIII No. 1.

Aucapiña et al. vs. Ministerio de Educación y Cultura, 31 de enero de 2001, Gaceta Judicial Serie XVII No. 5.

Avilés et al. vs. Avilés et al., 22 de febrero de 2001, Gaceta Judicial Serie XVII No. 5

Barberán et al. vs Iriarte et al., 19 de mayo de 2003, Gaceta Judicial Serie XVII No. 12.

Benítez vs. Fernández, 10 de noviembre de 1998, Gaceta Judicial Serie XVI No. 15.

Borja vs. Campos, 8 de mayo de 1997, Gaceta Judicial Serie XVI No. 9.

Bravo vs. Palma, 18 de junio de 2002, Gaceta Judicial Serie XVII No. 9.

Bucaram vs. Chejin, 21 de noviembre de 1996, Gaceta Judicial Serie XVI No. 7.

Buendía vs. Silva et al., 27 de mayo de 2009, Gaceta Judicial Serie XVIII No. 7.

Cadena vs. Jaramillo, 29 de marzo de 1999, Gaceta Judicial Serie XVI No. 15. 
Calle et al. vs. Muñoz et al., 5 de febrero de 2002, Gaceta Judicial Serie XVII No. 8.

Carbo et al. vs. Vergara et al., 18 de abril de 2007, Gaceta Judicial Serie XVIII No. 5.

Cárdenas vs. Armijos et al., 25 de febrero de 2006, Gaceta Judicial Serie XVII No. 2.

Chela vs. Rea, 11 de diciembre de 1996, Gaceta Judicial Serie XVI No. 7.

Chiriboga vs. Román, 19 de junio de 1880, Gaceta Judicial Serie I, No. 1.

Contraloría vs. Municipalidad de Cuenca et al., 18 de marzo de 2003, Gaceta Judicial Serie XVII No. 12.

Cooperativa de Vivienda Los Chasquis vs. Aseguradora del Sur, 8 de diciembre de 2009, Gaceta Judicial Serie XVIII No. 7.

Dávila vs. Salgado, 19 de marzo de 1996, Gaceta Judicial Serie XVI No. 5.

Diez vs. Yagua, 30 de julio de 2002, Gaceta Judicial Serie XVII No. 10.

Delgado et al. vs. Guerrón, 27 de junio de 1996, Gaceta Judicial Serie XVI No. 6.

Espinoza vs. Asociación Mutualista de Ahorro y Crédito para la Vivienda Azuay, 16 de noviembre de 2001, Gaceta Judicial Serie XVII. No. 7.

Figueroa et al. vs. Herederos de Bejarano, 29 de agosto de 2002, Gaceta Judicial Serie XVII No. 10.

Flores vs. Cooperativa de Vivienda de Ibarra, 22 de abril de 2002, Gaceta Judicial Serie XVII No. 9.

Freire vs. Navarrete, 21 de octubre de 1999, Gaceta Judicial Serie XVII No. 2.

Freire vs. Primera Zona Naval de la Armada Nacional, 6 de marzo de 2007, Gaceta Judicial Serie XVIII No. 3.

Garzón et al. vs. Zambrano et al., 24 de abril de 2000, Gaceta Judicial Serie XVII No. 3.

Gómez et al. vs. Gordillo et al., 17 de febrero de 1999, Gaceta Judicial Serie XVI. No. 14.

González et al. vs. González et al., 15 de enero de 2007, Gaceta Judicial Serie XVIII No. 3. 
González vs. Banco de los Andes, 18 de julio de 1996, Gaceta Judicial Serie XVI No. 6.

Heredia vs. Cervantes et al., 24 de abril de 2006, Gaceta Judicial Serie XVIII No. 2.

Jaramillo et al. vs. Heredia et al., 26 de marzo de 2001, Gaceta Judicial Serie XVII No. 5.

Jiménez et al. vs. Coello, 10 de octubre de 2002, Gaceta Judicial Serie XVII No. 10.

Layedra vs. Fuenmayor et al., 9 de abril de 2007, Gaceta Judicial Serie XVIII No. 5.

López et al. vs. Cauces et al., 22 de febrero de 1999, Gaceta Judicial Serie XVI No. 14.

López vs. López, 21 de febrero de 2003, Gaceta Judicial Serie XVII No. 11.

López vs. Pozo, 7 de julio de 1998, Gaceta Judicial Serie XVI No. 12.

Maza vs. Guamán, 25 de julio de 1998, Gaceta Judicial Serie XVI No. 12.

Mejía vs. Mejía et al., 28 de enero de 2003, Gaceta Judicial Serie XVII No. 12.

Mero et al. vs. Mero et al., 10 de marzo de 1998, Gaceta Judicial Serie XVI No. 11.

Miranda et al. vs. Pastor et al., 10 de febrero de 2005, Gaceta Judicial Serie XVIII No. 1.

Mirsky vs. Martinez, 17 de diciembre de 2003, Gaceta Judicial Serie XVII No. 14.

Montaño vs. Montaño, 16 de septiembre de 2004, Gaceta Judicial Serie XVIII No. 1.

Moreno vs. Superintendencia de Compañías y Citisur, 26 de octubre de 1998, Gaceta Judicial Serie XVI No. 13.

Municipio de Jipijapa vs. Toala et al., 25 de junio de 2004, Gaceta Judicial Serie XVIII No. 1.

Municipio de Quito vs DESACI, 9 de abril de 1996, Gaceta Judicial Serie XVI No. 5.

Municipio de Quito vs. DESACI, 28 de octubre de 1999, Gaceta Judicial Serie XVII No. 2. 
Ojeda vs. Luna, 3 de febrero de 2004, Gaceta Judicial Serie XVII No. 15.

Ortega vs. Burgos, 15 de septiembre de 1998, Gaceta Judicial Serie XVI. No. 13.

Parra vs. Samaniego, 14 de febrero de 2006, Gaceta Judicial Serie XVIII No. 2.

Paucra vs. Cruz, 22 de julio de 2002, Gaceta Judicial Serie XVII No. 10.

Paz et al. vs. Guambaña et al., 28 de julio de 2003, Gaceta Judicial Serie XVII No. 13.

Pérez et al. vs Hinojosa, 3 de marzo de 2006, Gaceta Judicial Serie XVIII No. 2.

Platzer vs. Platzer, 3 de diciembre de 1997, Gaceta Judicial Serie XVI No. 10.

Ponce vs. Amigos del Ecuador, 31 de octubre de 1995, Gaceta Judicial XVI No. 4.

Procurador General de la Nación vs. Fundación para la Educación y el Desarrollo, 15 de mayo de 1980, Gaceta Judicial Serie XIII No. 8.

Quirindumbay et al. vs. Japa et al., 6 de abril de 2009, Gaceta Judicial Serie XVIII No. 7.

Rengel vs Balseca et al., 14 de mayo de 1999, Gaceta Judicial Serie XVI No. 2.

Romero vs. Aguirre et al., 10 de enero de 2007, Gaceta Judicial Serie XVIII No. 3.

Romero vs. Medina, 1 de julio de 2004, Gaceta Judicial Serie XVIII No. 1.

Romero vs. Silva, 3 de abril de 2001, Gaceta Judicial Serie XVII No. 5.

Romero vs. Vicariato Apostólico, 3 de octubre de 2000, Gaceta Judicial Serie XVII No. 4.

Romo vs. Brito et al., 12 de julio de 2004, Gaceta Judicial Serie XV No. 15.

Sánchez vs. Sánchez et al., 24 de abril de 1997, Gaceta Judicial Serie XVI No. 8.

Solís vs. Aguilar et al., 14 de octubre de 2004, Gaceta Judicial Serie XVIII No. 1.

Sper vs. López, 23 de enero de 2007, Gaceta Judicial Serie XVIII No. 3. 
Tenenpaguay vs. Tenencota, 26 de abril de 2002, Gaceta Judicial Serie XVII No. 8.

Toledo vs. SICOMESA, 13 de abril de 1998, Gaceta Judicial Serie XVI No. 11.

Torres vs. Sánchez et al., 23 de septiembre de 2002, Gaceta Judicial Serie XVII No. 10.

Ulloa et al. vs. Filanbanco et al., Gaceta Judicial Serie XVII No. 10.

Valdiviezo et al. vs. Vásquez et al., 27 de mayo de 1996, Registro Oficial No. 72 del 26 de mayo de 1997.

Vélez vs. Solórzano, 21 de enero de 1998, Gaceta Judicial Serie XVI No. 12.

Wong vs. Bolivariano, 6 de mayo de 2004, Gaceta Judicial Serie XVII No. 14.

Yépez vs. Wood Vacation, 29 de agosto de 2001, Gaceta Judicial Serie XVII No. 7.

Zambrano et al. vs. López, 23 de febrero de 1999, Gaceta Judicial XVII No. 5.

Zamora vs. Zamora, 23 de abril de 1998, Gaceta Judicial Serie XVI No. 12.

Zhuzhingo vs. Siranaula, 21 de noviembre de 2003, Gaceta Judicial Serie XVII No. 14.

Zúniga vs Arias, 22 de enero de 2002, Gaceta Judicial Serie XVII No. 7. 